ISSN $0719-210 X$

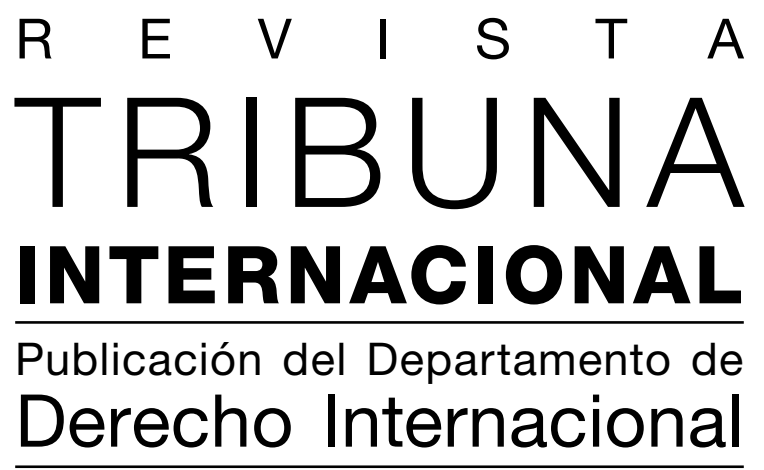

Volumen $2 / \mathrm{N}^{\circ} 3 / 2013$

FACULTAD DE

DERECHO 


\section{Rector de la Universidad de Chile}

Víctor Pérez Vera

Av. Alameda Libertador Bernardo

O'Higgins 1058, Santiago

\section{Representante legal}

Roberto Nahum Anuch

Decano de la Facultad de Derecho de la Universidad de Chile

\section{Director Responsable}

Mario Ramírez Necochea

\section{Editoras de Contenidos}

Rita Lages

Claudia Sarmiento Ramírez

\section{Comité Editorial}

Gonzalo Aguilar

José Carlos Fernández Rosas

Claudio Grossman

Mattias Kumm

Hugo Llanos

Cecilia Medina

Elina Mereminskaya

Mónica Pinto

\section{Comité de Árbitros}

Sergio Alburquenque Lillo (Chile)

Paulina Astroza (Chile)

Carolina Belmar (Chile)

María Paz Canales (Chile)

Alberto Coddou (Chile)

Zoya Galarza (Bolivia)

Nadia Franco-Bazán Ó Laighín (Panamá)

Rodrigo Lledó Vásquez (Chile)

Andrea Lucas Garín (Argentina)

Ignacio Mujica Torres (Chile)

Gloria Ramos Fuentes (Chile)

Marcela Ruiz Calderón (Chile)

Christian Sommer (Argentina)

Carolina Stefoni (Chile)

Gustavo Tocopillán (Argentina)

Miguel Torres (Cuba)

Cecilia Urbina (Chile)

Gustavo Luiz Von Bahten (Brasil)

\section{Revista Tribuna Internacional}

Publicación del Departamento de Derecho Internacional de la Facultad de Derecho de la Universidad de Chile Volumen 2 / No 3 / 2013 www.tribunainternacional.uchile.cl ISSN: 0719-210X

\section{Diseño y producción:}

Productora Gráfica Andros Ltda. www.androsimpresores.cl

Impreso en Chile/ Printed in Chile 


\section{ÍNDICE}

\section{Artículos}

Matrimonios entre personas del mismo sexo celebrados en el extranjero y sus efectos jurídicos en Chile. Análisis crítico del artículo 80 de la Ley de Matrimonio Civil

Pablo Andrés Cornejo Aguilera

La responsabilidad en el derecho penal internacional: una aproximación

desde la filosofía de John Searle. Reflexiones a partir del caso Lubanga

Rodrigo A. González Fernández y M. Soledad Krause Muñoz

Effectiveness of REDD programs in the protection of suigeneris

indigenous rights

Paloma Infante $M$.

Los usos. Si las inversiones y operaciones comerciales en diversos sectores

implican diversos riesgos y oportunidades, ¿por qué no se invocan

adecuadamente "los usos" en el procedimiento arbitral?

Hernany Veytia

\section{Comentarios de jurisprudencia}

La Orden de Medidas Provisionales del Tribunal Internacional del

Derecho del Mar en el caso del buque de guerra ARA Libertad

Martín Cabrera Mirassou

A Case of Equitable Maritime Delimitation: Nicaragua and Colombia in the Western Caribbean Sea

Paul S. Reichler 


\section{Recensiones}

"Guerra de las Malvinas. Noticia en desarrollo 1982-2012"

(Editorial El Mercurio, Santiago, 2012), de José Rodríguez Elizondo, por Juan Emilio Cheyre

"La Convención sobre Derechos del niño. Instrumento de progresividad en el Derecho Internacional de los Derechos Humanos"

(Editorial Dykinson, Madrid, 2011), de María del Rosario Carmona Luque, por Lucía Rizik Mulet 


\title{
La responsabilidad en el derecho penal internacional: una aproximación desde la filosofía de John Searle. Reflexiones a partir del caso Lubanga ${ }^{1}$
}

Responsibility in the international criminal law: an approach from John Searle's philosophy. Reflections upon the Lubanga trial

\section{Rodrigo A. González Fernández}

rodgonfer@gmail.com

PhD in Philosophy (Bélgica), Master in Philosophy (Bélgica), Magíster en Filosofía (Chile), Licenciado en Filosofía (Chile), Profesor de Filosofía de la Universidad de Chile.

\section{Soledad Krause Muñoz}

skrausem@gmail.com

Abogada (Chile), Doctora en Derecho Penal y Ciencias Penales (España), Magíster en Filosofía (Chile), Licenciada en Ciencias Jurídicas y Sociales (Chile).

We are enmeshed in systems of deontic powers.

John Searle ${ }^{2}$

\begin{abstract}
Resumen: En este trabajo examinamos el tópico de la responsabilidad en el derecho penal internacional a la luz de la filosofía de John Searle, y del fallo dictado por la Corte Penal Internacional en el caso de Thomas Lubanga. En el primer acápite analizamos la declaración de responsabilidad penal en función de la teoría de actos de habla de Austin y de Searle, tratándola como un acto ilocucionario cuyo significado es dependiente de un marco institucional específico. Luego, en el segundo acápite, mostramos de qué forma tal marco puede reconstruirse como un ejemplo paradigmático de la realidad social construida descrita por Searle, especialmente en virtud del nexo entre mente, lenguaje y sociedad. A nuestro juicio, los conceptos de intencionalidad colectiva, atribución de funciones de estatus y poderes deónticos son fundamentales para entender tal nexo. En efecto, tal como argumentamos en la tercera sección, los sistemas de poderes deónticos asociados al derecho internacional no solo explican la
\end{abstract}

1 Fecha de recepción: 14.03.2013 y fecha de aceptación: 24.04.2013.

2 SeArle, John. Making the social world. Oxford: OUP, 2010, p. 130. 
aparición de Tribunales penales internacionales, como la Corte Penal Internacional, sino además el carácter imprescriptible de los crímenes de lesa humanidad. Los acuerdos internacionales que promueven y protegen los derechos humanos, y que tratan la imprescriptibilidad de aquellos crímenes, son objeto de análisis en la sección final, en donde exponemos algunas reflexiones finales a partir del caso Lubanga.

Palabras clave: derecho penal internacional, declaraciones, responsabilidad, intencionalidad colectiva, poderes deónticos, caso Lubanga.

Abstract: This article deals with the issue of responsibility in international criminal law in light ofJohn Searle's philosophy as well as Thomas Lubanga decision at the International Criminal Court. In the first section, we analyze the declaration of criminal responsibility in function of Austin and Searle's theory, considering it as an illocutionary act the meaning of which depends upon a specific institutional framework. We show, in the second section, how this framework can be construed as a paradigmatic example of Searle's construction of social reality, especially in virtue of how mind, language and society interact. As far as we are concerned, concepts such as collective intentionality, status functions attributions and deontic powers are crucial to understand that link. Indeed, as we argue in the third section, the systems of deontic powers associated with international law, such as the International Criminal Court, not only elucidate international criminal courts, but also the imprescriptibly of crimes against humanity. International agreements that promote and protect human rights, which deal with the imprescriptibly of those crimes, are addressed in the final section, where we also show a number of reflections upon the Lubanga trial.

Keywords: International criminal rule of law, declaratives, responsibility, collective intentionality, deontic powers, the Lubanga trial.

\section{Introducción}

El presente trabajo examina la declaración de responsabilidad en el derecho internacional como un acto de habla, y plantea su reconstrucción como un hecho institucional al que pueden aplicársele las herramientas teóricas propuestas por John Searle. En función de tales herramientas argumentamos aquí que tal derecho y la institucionalidad en que se aplica representan un trascendental sistema de poderes deónticos que establecen responsabilidad a nivel internacional y que, por lo mismo, trascienden el ámbito de culturas o prácticas sociales particulares. Ellas se aplican al caso de Thomas Lubanga, fallado por la Corte Penal Internacional en 2012, a propósito del cual se demuestra cómo la responsabilidad surge a la realidad social como un hecho institucional, y la importancia 
que en ello tienen los sistemas de poderes deónticos y las instituciones extralingüísticas, como sucede con los tribunales internacionales.

En el primer apartado analizamos las declaraciones como una especie de actos ilocucionarios, exponiendo la relevancia que presentan sus caracteres para explicar la forma en que surgen a la realidad social. En el segundo apartado vinculamos los actos de habla con la mente y la sociedad, explicando el modo en que se relaciona el lenguaje con la institucionalidad colectiva. En el tercer acápite, aplicamos los argumentos desarrollados con precedencia a la declaración de responsabilidad en el derecho internacional penal y, en concreto, al caso fallado por la Corte Penal Internacional en el caso de Thomas Lubanga, ofreciendo algunas de las razones que explican el interés y la utilidad de examinar la responsabilidad como una institución social que surge bajo la aplicación de reglas constitutivas. En la cuarta examinamos uno de los caracteres de la responsabilidad penal internacional a la luz de los criterios ofrecidos: su imprescriptibilidad.

\section{El rol de las declaraciones en el contexto de los actos de habla}

Cuando hablamos de responsabilidad penal internacional nos referimos, si se atiende al discurso de los últimos años ${ }^{3}$, a procesos internacionales en que se persigue la sanción de individuos por graves violaciones a derechos humanos y al derecho internacional, primero seguidos ante tribunales ad hoc constituidos para ciertos conflictos, y tras la aprobación del Tratado de Roma, ante la Corte Penal Internacional (CPI ${ }^{4}$. En ambos casos, la responsabilidad es el resultado de una declaración efectuada por un tribunal, y se materializa en un acto formal que la establece. La decisión que la contiene es el producto de un proceso en que se afirma que un individuo (aquel en contra del que se ha incoado el procedimiento, en relación con cuya intervención en los hechos acaecidos

3 Una descripción de esas transformaciones en Aguilar, Gonzalo. "Justicia internacional penal: un pilar del Estado de derecho internacional”. Revista Tribuna Internacional [en línea]. Vol. 2, No 1, 2012. Disponible en http://www.tribunainternacional.uchile.cl/. ISSN: 0719-210X. [Fecha de consulta: 18 febrero 2013].

4 Амвоs, Kai. "El derecho penal internacional en la encrucijada: de la imposición ad hoc a un sistema universal basado en un tratado internacional". Política Criminal [en línea]. Vol. 5, No 9, 2010, p. 222. Disponible en: www.politicacriminal.cl. ISSN: 0718-3399. [Fecha de consulta: 6 febrero 2013]. 
y calificados como crímenes se ha rendido prueba, y quien se ha defendido) es o no culpable de los ilícitos que se le han atribuido. La pena impuesta, en el evento de que se resuelva afirmativamente la interrogante, es una consecuencia de esa declaración previa.

Así vista, la responsabilidad en el ámbito del derecho penal internacional, aunque no solo en este, surge de un acto de habla, el que al ser proferido por un determinado sujeto, en cierto contexto, y bajo ciertas y determinadas reglas, permite el nacimiento de una realidad social nueva - de una institución social, se dirá- que, antes de esa declaración y sin esta, no existiría.

El hecho de que ello suceda y el modo concreto en que lo hace, constituye el tópico que abordaremos en lo que sigue. Para ello parece necesario, no obstante, detenernos en dos herramientas necesarias para comprender este proceso, y que son aportaciones de la teoría de los actos de habla desarrollada por Austin y Searle ${ }^{5}$ la teoría de la construcción de la realidad social planteada por este último ${ }^{6}$.

Según pone de manifiesto Austin, al proferir determinadas palabras no nos limitamos a describir una realidad que existe con independencia de los sujetos, y de esas mismas expresiones. En muchos casos, y en varios contextos, las palabras crean hechos nuevos. El ámbito de lo jurídico es particularmente prolífico en ejemplos. Así, cuando el oficial del Registro Civil declara casados a los contrayentes no se limita a describir el matrimonio ya existente entre los cónyuges, sino a celebrarlo; y cuando comprador y vendedor acuerdan una compraventa dan origen a un contrato, y no solo informan sobre un vínculo económico o patrimonial precedente. Sin embargo, supuestos en los que las palabras se utilizan con esta fuerza no solo se encuentran en el mundo jurídico. Cuando una persona acepta una invitación que otro le ha formulado, promete asistir; y cuando una persona se excusa por lo sucedido, se disculpa. En estos casos, en el mundo del derecho, y en el social en general, las palabras proferidas no se limitan a describir o informar acerca de lo existente, sino a dar origen a nuevos hechos que sin ellas, o al margen de las mismas, no podrían surgir. Tales hechos -y la realidad a la que dan origen- son convencionales, y en ese entendido, producto de un acuerdo, que surge

5 Austin, John. How to do things with words. Harvard: HUP, 1975, passim; Searle, John. Actos de habla, traducción de Luis Valdés Villanueva, Madrid: Editorial Cátedra, 2007, passim.

6 SeArle, John. The construction of social reality. London: Penguin Books, 1995. 
precisamente porque quien las dice (y la sociedad de la que este forma parte) dan a determinadas palabras un uso, y de acuerdo con ciertas reglas, el poder (o la función) de producir los efectos que en definitiva generan.

En el caso de la declaración de responsabilidad nos encontramos con un supuesto en que las palabras proferidas por un sujeto determinado (el tribunal), en un cierto y determinado contexto (al término del juicio, finalizado el procedimiento y cumplidas las formalidades de tiempo, lugar y competencia, entre otras) hacen posible el nacimiento de una realidad social nueva: que una persona se transforme en responsable de un crimen, y a consecuencia de ello, se produzcan una serie de efectos dentro de los cuales se encuentra el deber de este de soportar una determinada pena, y la reconfiguración de la identidad de la persona del responsable (quien adquiere un nuevo estatus: el de condenado).

Teniendo en cuenta el poder que tiene el lenguaje para crear nuevos hechos, parece necesario reconocer, como dice Austin, que decir es hacer al menos en tres sentidos diferentes 7 . En un primer sentido, como acto de emisión de ciertas palabras con una determinada construcción gramatical, con un sentido y una referencia (como acto locucionario: acto que se realiza por decir algo). También en un segundo sentido, decir es hacer por cuanto las palabras se pronuncian con una determinada fuerza e intencionalidad, de manera que proferirlas importa la realización de determinados actos como preguntar, informar, ordenar, prometer, exhortar, etcétera (acto ilocucionario: el acto que se realiza al decir algo). Finalmente, decir algo produce o puede generar consecuencias en los sentimientos, pensamientos o acciones de quien emite la expresión, del auditorio o de terceros y es posible que el acto se realice, además, con el propósito de realizarlo (acto perlocucionario: acto que se realiza porque se dice algo).

Las declaraciones -como sucede con la declaración de responsabilidad-son una especie de actos ilocucionarios que surgen por la aplicación de reglas que podemos denominar constitutivas, en la medida en que hacen posible la realidad misma que surge con su aplicación, y que importan la asignación de una función o la creación de poderes deliberados o arbitrarios a objetos, sujetos o procesos. Su forma puede describirse bajo la regla de $X$ cuenta como $Y$ en $C$, en el entendido que ciertas expresiones proferidas con

Austin, John. How to do things with words. Harvard: HUP, 1975. 
un determinado sentido y referencia $(X)$ asignan funciones o poderes convencionales (cuentan como $Y$ ) en un cierto contexto $(C)$.

Las declaraciones presentan ciertas características peculiares que las diferencian de los demás actos ilocucionarios. La más distintintiva, es que el estado de cosas que representan es realizado por el dispositivo de fuerza ilocucionaria, de manera que a propósito de ellas es particularmente claro que decir es hacer ${ }^{8}$. Si la declaración es realizada con éxito, en el mundo se realiza aquello que la declaración pretende crear, de manera tal que este se transforma a consecuencia de las palabras, lo que permite argumentar que la dirección de ajuste de las mismas es doble: palabras a mundo y mundo a palabras?.

Las declaraciones, para producir los efectos que le son propios, esto es, crear una realidad social sin ellas inexistente, exigen un conjunto de instituciones extralingüísticas. Muchas de esas instituciones son, a su vez, aplicación de otras reglas constitutivas, de manera que se advierten como fases previas de una misma cadena en que iteradamente se constituye la realidad social.

Según se advierte de esta sucinta exposición, las declaraciones son actos de habla que tienen la particularidad de dar origen a nuevos hechos en el mundo social. En la medida en que la responsabilidad es el resultado de una declaración, ella surge como un producto esencialmente convencional y lingüístico, y como una clase particular de hecho institucional de aquellos a los que haremos referencia en el siguiente acápite. Ciertamente, resulta necesario aclarar cómo se conecta mente, lenguaje y sociedad para comprender de mejor forma la aparición de la realidad institucional y, en este contexto, la responsabilidad en el derecho penal internacional.

8 Searle, John. Mind, language and society. New York: Basic Books, 1998.

9 SeArle, John. "Qué es un acto de habla”, En: VAldÉs, Luis (comp.), La búsqueda de significado, 4a. edición, Madrid: Editorial Tecnos, 2005, pp. 461-462: "el estado de cosas representado en la proposición expresada es realizado o traído a la existencia por el dispositivo indicador de fuerza ilocucionario, casos donde se trae a la existencia un estado de cosas declarando que existe, casos donde, por así decirlo, 'decir es hacer"”. 


\section{La conexión entre mente, institución y racionalidad institucional}

Nuestro objetivo en esta sección es examinar el continuo entre la teoría de los actos de habla y la filosofía de la mente de Searle, lo cual ayudará a comprender la síntesis que realiza entre mente, lenguaje y sociedad.

Tal como este filósofo declara, el continuo se refleja en el isomorfismo entre los actos de habla y los estados mentales intencionales, como los actos ilocucionarios, por una parte, y las creencias y deseos, por otra. Por esta razón, los actos ilocucionarios y los estados mentales intencionales tienen condiciones de satisfacción y dirección de ajuste, sean condiciones de verdad u otras. También, y tal como analizamos brevemente más arriba, en la mayoría de los actos ilocucionarios y los estados mentales intencionales hay adecuación entre lenguaje y mundo, o entre mente y mundo (o viceversa, para ambos casos). Esto se explica porque la capacidad de representar del lenguaje proviene de la intencionalidad de los estados mentales, que a su vez se explica por una capacidad del cerebro $^{10}$. Solo en función de esta capacidad puede comprenderse el nexo entre intencionalidad, representación, significado y comunicación ${ }^{11}$.

10 Searle, John. Mind, language and society. New York: Basic Books, 1998, pp. 138-139: “¿Cómo Ud. llega del sonido al tipo de actos ilocucionarios?’ Es en verdad la misma pregunta que ‘¿Cómo la mente confiere significado sobre la base de puras marcas y sonidos?' Y la respuesta a esa pregunta nos dará un análisis del concepto de significado que podemos usar para explicar cómo el lenguaje se relaciona con la realidad. El lenguaje se relaciona con la realidad en virtud del significado, pero esta es la propiedad que transforma meras proferencias en actos ilocucionarios. Estos son significativos en un sentido muy especial de la palabra, y es esta clase de significatividad lo que permite al lenguaje relacionarse con la realidad. Entonces, al final, entendidas de manera correcta, las tres preguntas '¿qué es el significado?', '¿cómo el lenguaje se relaciona con la realidad?' y ‘ ‘cuál es la naturaleza del acto ilocucionario?’ son la misma. Como se examinará, las tres versan sobre cómo la mente impone intencionalidad sobre sonidos y marcas, así confiriendo significados a estas de forma que las relaciona con la realidad".

11 Ibid., p. 141: "La clave para entender el significado es esta: el significado es una forma de intencionalidad derivada. La intencionalidad original o intrínseca del pensamiento de un hablante se transfiere a las palabras, oraciones, marcas, símbolos y similares. Si se profieren de manera intencional, aquellas palabras, oraciones, marcas y símbolos ahora tienen intencionalidad derivada de los pensamientos del hablante. No tienen solo significado lingüístico convencional, sino el significado intencional del hablante. La intencionalidad convencional de palabras y oraciones de un lenguaje pueden usarse por un hablante para llevar a cabo un acto de habla. Cuando un hablante lleva a cabo un acto de habla, impone su intencionalidad en aquellos símbolos". 
La mente/cerebro impone significado a sonidos y signos, lo cual permite la comunicación y, de manera crucial para la creación de la realidad social mediante las mencionadas declaraciones, la atribución de funciones. Así, a pesar de que el objetivo central de la filosofía de la mente de Searle ha sido disolver el problema mente-cuerpo, con creces ha excedido tal reto. Su propuesta no solo intenta responder qué es la mente, sino que además ha contribuido a elucidar la dependencia que tiene la realidad social (e institucional) respecto del lenguaje y la intencionalidad, tanto individual como colectiva.

Sin embargo, para entender la síntesis entre mente, lenguaje y sociedad es necesario examinar en forma breve cómo Searle trata de disolver el problema mente-cuerpo. De acuerdo con su teoría ${ }^{12}$, dualismo y materialismo habrían sido inspirados por una distinción cartesiana ingenua entre lo físico y lo mental, según la cual hay dos sustancias independientes entre sí, o una sola clase de cosa en el mundo, respectivamente. Más aún, mientras que el dualista sostiene que mente y objetos físicos tienen características metafísicamente diversas, como la no extensión y la divisibilidad, el materialista intenta reconciliar la mente con el mundo material y las aproximaciones científicas a este. Pero pese a sus aspectos positivos, dualismo y materialismo por último terminan por soslayar aspectos esenciales de la naturaleza de la mente.

Por una parte, el dualismo hace de la mente una entidad difícil de explicar mediante investigación científica. Por cierto, al considerarla totalmente distinta de las cosas físicas, no resulta susceptible de ser explorada por las ciencias. El extremo de esta posición lleva a considerar este fenómeno como inexplicable desde un punto de vista científico, y ello hace que cuente para algunos como un misterio ${ }^{13}$.

Por otra, aunque el materialismo no renuncia a estudiar la mente como un fenómeno natural, su consideración de la experiencia y la conciencia como reductibles a lo físico hace que muchos sientan que es una posición dogmática. En efecto, el materialista niega que exista algo real e irreductible más allá de los puros hechos y eventos físicos. No obstante, cabe preguntar lo siguiente: si la mente es un fenómeno natural, ¿̨por qué no estamos dispuestos a reducirla metafísicamente como en los casos de agua $=\mathrm{H}_{2} \mathrm{O}$,

12 Ibid. También: Searle, John. Mind: A brief introduction. Oxford: OUP, 2004.

13 Nagel, Thomas. The view from nowhere. New York: OUP, 1986. También: McGinn, Colin. "Can we solve the mind body problem?" Mind, (98): 349-66, 1989. ISSN: 1460-2113. 
calor $=$ promedio de energía cinética molecular, luz = haz de fotones? Con seguridad, la reducción de estos fenómenos no semeja qué sucede con la mente, porque no resulta satisfactorio afirmar que, por ejemplo, el dolor es solo y nada más que activación de las fibras C. La posibilidad de imaginar la activación de estas fibras y que no haya dolor, o que exista este y no haya activación de fibra alguna muestra que la reducción metafísica de la mente al cerebro es controvertida ${ }^{14}$.

A nuestro juicio, la dificultad más importante que presentan dualismo y materialismo es que no permiten explicar el continuo que existe entre mente y realidad física y social. Por tal motivo, Searle plantea una teoría alternativa sobre lo mental denominada "naturalismo biológico". Puesto de una manera breve y simple, dicho enfoque trata la mente como un fenómeno biológico, similar a la digestión o a la oxidación celular. En relación con el problema mente-cuerpo, esta posición superaría tanto al dualismo como al materialismo, pues trata con la experiencia consciente como un fenómeno que puede ser explicado por las ciencias, pero no reducido metafísicamente respecto del punto de vista de primera persona que involucra, por ejemplo, cuando alguien tiene sed ${ }^{15}$.

No es sorprendente entonces que dicho naturalismo biológico abogue por el antirreduccionismo metafísico de la conciencia, pese a que puede ser estudiada como un fenómeno biológico. En este sentido, la teoría de Searle asume que lo mental es causalmente reductible, pues puede explicarse causalmente en términos neurales, tal como la impenetrabilidad y la solidez se elucidan por la conducta molecular. Pero hay una importante diferencia entre estos casos y la mente. Aunque la solidez no es más que las causas subyacentes que explican el fenómeno superficial, lo mismo no ocurre con el caso de la conciencia, porque si bien puede haber una explicación causal del fenómeno, la subjetividad ${ }^{16}$ y el punto de

14 KRIPKE, Saul. Naming and necessity. Cambridge, Mass.: Harvard University Press, 1980.

15 Searle, John. Mind: A brief introduction. New York, OUP, 2004, p. 79: “Todas las formas de conciencia son causadas por la conducta de las neuronas y son realizadas en el cerebro, el cual está compuesto de neuronas. Lo que sucede con la sed ocurre con absolutamente todas las formas de conciencia, desde tener asco estomacal hasta preguntarse cómo traducir los poemas de Stéphane Mallarmé al inglés coloquial. Todos los estados conscientes son causados por procesos neurales de bajo nivel en el cerebro. Tenemos pensamientos conscientes y sentimientos; son causados por procesos neurobiológicos en el cerebro, y existen como características biológicas del sistema nervioso. [...] Llamo a mi postura naturalismo biológico porque proporciona una solución naturalista al problema tradicional mente-cuerpo, uno que enfatiza la naturaleza biológica de los estados mentales, y evita tanto el materialismo como el dualismo".

16 No debe confundirse la subjetividad metafísica de la conciencia, su modo de existir, con la subjetividad de los juicios, de índole epistémica. Esta última tiene que ver con el valor de verdad de algunas oraciones, que 
vista de primera persona que implica, quedan fuera cuando es reducida metafísicamente a lenguaje objetivo, cuya perspectiva es de tercera persona ${ }^{17}$.

De este modo, para Searle los estados mentales tienen constitutivamente un punto de vista de primera persona. Este aspecto de la conciencia está directamente relacionado con su subjetividad, el modo de existencia de este fenómeno, que da origen a lo que él denomina "ontología de primera persona”, y que como analizamos más abajo, es crucial para comprender el modo de existencia de la realidad social ${ }^{18}$. En contraposición a esta subjetividad ontológica, Searle considera que hay fenómenos cuyo modo de existencia es de tercera persona. Por ejemplo, objetos como los electrones, las placas tectónicas, las galaxias y los virus. Todos estos tienen modos de existencia que no depende en forma alguna de un observador, y menos aún de una perspectiva. Por el contrario, existen con independencia de que alguien observe o tenga perspectiva subjetiva.

El problema de la naturaleza de la mente tiene una importante consecuencia para la realidad social. Desde el punto de vista metafísico u ontológico, los modos de existencia de primera y de tercera persona se apoyan en una distinción que permitiría superar, según Searle, el problema mente-cuerpo heredado desde Descartes. Brevemente, la distinción consiste en identificar los objetos que son observador (mentalmente) independientes, y los que son observador (mentalmente) dependientes. Entre los primeros están los mencionados electrones, placas tectónicas, galaxias, virus, entre un sinnúmero de objetos que caen en esta categoría. Entre los segundos, en cambio, hay aquellos cuya existencia depende crucialmente de observadores con estados mentales intencionales, es decir, de la capacidad de representar y reconocer. Por ejemplo, los matrimonios, los partidos de fútbol, las corporaciones, el dinero, los juicios penales internacionales, entre muchos otros objetos, eventos y entidades, son objetos de la realidad social.

depende de valoraciones, sentimientos y prejuicios de sujetos. Por ejemplo, "Van Gogh es mejor pintor que Miguel Ángel”. En cambio, hay otros juicios cuya verdad es objetiva epistémicamente. Por ejemplo, "Chile se independizó en 1810 de la corona española”. Esta distinción es importante, según Searle, porque el modo de existencia de primera persona de la conciencia no implica que no pueda estudiarse objetivamente. SEARLE, John. Mind, language and society. New York: Basic Books, 1998, pp. 43-4. 
Tal como remarcamos en este trabajo, Searle considera que el estudio de la realidad social debe necesariamente conducirse de acuerdo con dos de sus teorías en filosofía de la mente: los actos de habla y la intencionalidad ${ }^{19}$. Esta metodología no solo debe verse como una estrategia explicativa de este filósofo, sino que además podría interpretarse como un afán de proponer un sistema que permita comprender toda la realidad, tanto física como social, cuestión que es ciertamente poco frecuente en la filosofía contemporánea.

Sea como fuere, es claro que la distinción entre objetos observador dependientes e independientes es paralela a la de hechos brutos y hechos institucionales, la cual puede caracterizarse en términos de la diferencia entre reglas regulativas y reglas constitutivas. Las primeras son "naturales", en el sentido de que regulan acciones que ya existían antes de la creación de la regla (por ejemplo, desplazarse en un vehículo por la pista derecha); en cambio, las segundas, además de depender de la intencionalidad colectiva de ciertos agentes, constituyen ciertas actividades (e.g., la regla del enroque, entre otras, ayuda a configurar qué es jugar ajedrez).

Un par de ejemplos ilustrarán qué entiende Searle por hechos brutos e institucionales. Mientras que es un hecho bruto que la masa de la luna es $7.349 \times 10^{22} \mathrm{~kg}$, es un hecho institucional que Barack Obama es el actual presidente de los Estados Unidos. Cabe destacar que existe dependencia de los hechos institucionales en los brutos, porque aquellos necesitan realizarse físicamente y, además, ser pensados mediante estados mentales, y ser declarados por medio del lenguaje para que sean reconocidos colectivamente ${ }^{20}$. Así, queda clara la síntesis entre mente, intencionalidad y lenguaje. La conciencia posee cierta subjetividad metafísica con la cual la mente individual se relaciona con el mundo, mientras que la intencionalidad y el lenguaje, con su capacidad de representar y declarar colectivamente, hacen que aparezcan los hechos institucionales.

19 Searle, John. Mind, language and society, New York: Basic Books, 1998, p. 112: "Empleo mi teoría de la mente para proporcionar una explicación de la naturaleza de la realidad social e institucional". También: SEArLe, John. Making the social world. New York: OUP, 2010, p. 3: “¿Cómo es posible que en un universo consistente en partículas físicas en campos de fuerza haya cosas como la conciencia, la intencionalidad, la voluntad libre, el lenguaje, la sociedad, la ética, la estética, y las obligaciones políticas? Aunque muchos, a lo mejor todos los filósofos contemporáneos no tratan este problema directamente, creo que es una pregunta crucial en la filosofía contemporánea. He dedicado gran parte de mi vida profesional a varios aspectos de la misma. Este libro usa mis teorías de la intencionalidad y de los actos de habla para explicar la realidad ontológica".

20 Searle, John. The construction of social reality. London: Penguin Books, 1995, pp. 34-35. También: Searle, John. Mind, language and society. New York: Basic Books, 1998, pp. 121-3. 
A diferencia de los hechos brutos, que son observador-independientes, los hechos institucionales, de carácter jerárquico, son fundamentales para entender como existe toda la realidad social. Para comprender los últimos es necesario recordar que tal como la mente impone intencionalidad y significado a marcas y sonidos, lo mismo ocurre con objetos, personas y entidades. En concreto, la mente atribuye funciones de estatus a los últimos. Pero esto es una actividad que se desarrolla colectivamente en el ámbito social, cuestión que ocurre cuando se asigna una función a objetos, personas o entidades, y por esta vía obtienen un nuevo estatus reconocido colectivamente. En general, estas funciones son atribuidas de acuerdo con las reglas constitutivas que mencionamos más arriba. Justamente, de la interrelación entre reglas constitutivas y funciones de estatus se origina la mencionada fórmula $X$ cuenta como $Y$ en $C$. Es decir, se aplican ciertas reglas a un objeto o personas en la realidad $(X)$; a este se le asigna mediante intencionalidad colectiva una función o estatus que no es producto de su configuración original, o de sus propiedades físicas intrínsecas. Por este motivo, el objeto cuenta como $Y$ en cierto contexto, y según las condiciones $(C)^{21}$.

Si esto sucede, pese a que la cosa(s) o la persona(s) tienen propiedades físicas, el nuevo estatus que se les ha conferido impone una función, como ocurre con una frontera, una propiedad privada, un presidente, un profesor universitario, etcétera. La comunidad

21 Searle, John. Making the social world. New York: OUP, 2010, pp. 94-5, énfasis en original: "En escritos previos [La construcción de la realidad social, London: Penguin Books, 1995] describí cómo los hechos institucionales podrían evolucionar de hechos físicos no institucionales. Imaginé una tribu que construye un muro alrededor de sus chozas, donde dicha muralla cumple la función de restringir el acceso en virtud de su estructura física, porque es muy alta para ser escalada fácilmente. Entonces imaginamos que la muralla se cae hasta no quedar nada más que una línea de piedras. Pero supongamos ahora que los habitantes y los foráneos continúan reconociendo la línea de piedras como cumpliendo cierto estatus: uno que podría describirse como un límite. Y ellos continúan reconociendo que ellos no deben cruzar el límite a no ser que se les autorice. [...] En este caso comenzamos con un objeto que desarrolla su función en virtud de su estructura física. Pero evoluciona a un objeto que desarrolla su función, no gracias a su estructura física, sino a que hay un reconocimiento o aceptación colectiva, tanto de quienes están dentro como fuera del límite, de que la línea tiene cierto estatus y desarrolla su función solo en virtud del reconocimiento colectivo o la aceptación de ese estatus. Esto es un ejemplo de una "función de estatus". Definiré una función de estatus como una función que desempeña un objeto(s), persona(s) u otro tipo de entidades y que pueden desarrollarse gracias a que la comunidad en la cual la función se desarrolla asignando cierto estatus al objeto, persona o entidad involucrada, y la función se desempeńa en virtud de la aceptación colectiva o el reconocimiento de que el objeto, persona o entidad tienen cierto estatus [...]

El caso de la muralla teniendo la función de estatus de ser un límite no requiere de lenguaje escrito o regla general. En este caso, la gente involucrada impone una función de estatus $\mathrm{Y}$ a un objeto X en un contexto C”. 
reconoce en estos una función que no tiene que ver con propiedades físicas, sino con el estatus que se les ha otorgado y que les significa un nuevo reconocimiento colectivo.

Cabe destacar que la intencionalidad colectiva es crucial para asignar las funciones de estatus. Dicha intencionalidad se origina a partir de la intencionalidad de cada cerebro, pero no se reduce a esta ni a su carácter individual ${ }^{22}$. Por el contrario, consiste en la capacidad que tienen las personas de actuar cooperando, lo cual lleva a establecer nuevas funciones a objetos y a reconocer las mismas a través del tiempo. El sentido de la cooperación tiene tanto que ver con ciertas acciones colectivas, como con creencias, deseos y otras actitudes compartidas. Es decir, la intencionalidad colectiva sintetiza intenciones acerca del compromiso de un grupo, o bien la intención-en-la-acción de este, que se reflejan en oraciones como: "Nosotros tenemos como intención llevar a cabo A" y "Nosotros estamos (intencionalmente) llevando a cabo A"23, respectivamente. En ambos casos existe cooperación colectiva porque hay un pacto, una promesa solemne o una obligación suscrita por parte de los miembros de un grupo, y esto ocurre incluso si los estados mentales intencionales asociados ocurren en cerebros individuales. Ello no obsta a que pueda existir cooperación en las acciones colectivas que se realizan, lo cual implica la existencia de conocimiento común o creencia común (pero estos, junto con intenciones individuales, no son suficientes para que haya cooperación).

Los ejemplos de intencionalidad colectiva son múltiples en la sociedad, e incluso en el reino animal: una cámara votando un proyecto de ley, un equipo jugando fútbol, músicos tocando en una orquesta, o un par de cuervos distrayendo a un águila para robar sus huevos $^{24}$. Lo único que se requiere en todos estos casos es la existencia de sujetos, que colectivamente sean capaces de atribuir funciones a objetos, asignándoles un propósito. Estas son las denominadas "funciones agentivas" 25 , que son siempre intencionalmente relativas, es decir, los propósitos asignados no existen en la naturaleza, como en el caso del corazón o los pulmones, sino que son relativos a un conjunto de valores, lo cual se refleja en el lenguaje normativo con que pueden describirse.

\footnotetext{
Op. cit., pp. 43-4, 46 y, especialmente, 47-8.

Op. cit., p. 46.

24 Konnblith, Hilary. Knowledge and its place in nature. Oxford: OUP, 2002, pp. 37-42.

25 SeArle, John. Making the social world. New York: OUP, 2010, p. 58.
} 
Dos cuestiones son cruciales respecto de las funciones de estatus y la intencionalidad colectiva. Por una parte, aquellas necesitan de esta para ser creadas y mantenidas. Por otra, tales funciones son ajenas a las propiedades físicas de objetos y personas, ya que existen solo en virtud de la imposición colectiva y el reconocimiento de cierto estatus, cuestión que puede ocurrir iteradamente, es decir, se pueden reiterar funciones para un mismo objeto.

Ambos aspectos están relacionados con el carácter subjetivo-ontológico con que existe la realidad social e institucional: solo lo hace en virtud de actitudes subjetivas. De este modo, la realidad social tiene un modo de existencia ontológicamente subjetivo, porque no existe en la naturaleza de la misma forma que árboles, placas tectónicas, galaxias y virus. Aún así, la realidad social es epistémicamente objetiva, porque los enunciados que podemos hacer sobre los hechos institucionales no dependen de valoraciones o prejuicios personales ${ }^{26}$. Pero ¿cómo se preserva la realidad institucional si depende de actitudes subjetivas? Y, más aún, ¿cómo se reconoce socialmente? Un elemento que ayuda a la mantención y el reconocimiento de las funciones de estatus son las marcas de estatus, las cuales no requieren de la proximidad física o de la posesión efectiva de un objeto o un bien. Entre dichos marcadores se cuentan los anillos, los certificados, los pasaportes, las insignias, los uniformes, etc. ${ }^{27}$, todos los cuales responden a la iteración de funciones que mencionamos arriba.

También resulta crucial que destaquemos que las funciones de estatus y los marcadores se relacionan con la aparición de poderes deónticos; estos, junto con la iteración de funciones de estatus, explican la dinámica de la realidad social. Tales poderes consisten en que, una vez que se asignan las funciones de estatus de manera reiterada, comienzan a operar derechos, deberes, obligaciones, requerimientos, permisos, autorizaciones, etcétera. Pueden ser de naturaleza positiva (un derecho) o negativa (una obligación). Aún así, lo esencial de los poderes deónticos es que dan razones para la acción independientes-dedeseos ${ }^{28}$; por ejemplo, ciertos poderes deónticos mandan a un profesor a dar una clase en cierto día y horario, porque tiene tanto un compromiso con sus estudiantes como una obligación institucional. Asimismo, la mera existencia de las instituciones confiere

26 Op. cit., p. 18.

27 SeArle, John. The construction of social reality. London: Penguin, p. 85. También: Mind, language and society. New York: Basic Books, p. 156. 
una serie de posibilidades que no existirían de otra forma, lo cual se vincula con la racionalidad. Mientras que las posibilidades otorgan razones para la acción, estas son independientes-de-deseos, porque no dependen de lo que sintamos o deseemos en un momento determinado ${ }^{29}$. Luego, las obligaciones dan lugar a razones independientesde-deseos, en línea con la realidad institucional y su racionalidad.

Ahora bien, una cuestión fundamental relacionada con las declaraciones es que tanto la creación de la realidad institucional como los poderes deónticos que conlleva son dependientes del lenguaje. Esto ocurre porque la racionalidad debe representarse lingüísticamente para que así opere como representaciones de alto nivel. Solo estas permiten que reflexionemos sobre nuestras creencias y deseos, y que optemos por razones institucionales consistentes con la racionalidad. En efecto, los poderes deónticos deben ser representados de alguna manera, tal como la realidad institucional debe crearse por medio de declaraciones. Mediante la capacidad realizativa del lenguaje que destacamos en la sección previa, las declaraciones son capaces de crear hechos institucionales, al igual que las obligaciones, derechos, compromisos, etcétera, que emanan de estos.

En síntesis, para Searle existe un vínculo entre lo mental, lo institucional y la racionalidad. La mente tiene capacidad de relacionarse con el mundo por medio de la conciencia, pero esta no es suficiente para operar en la realidad. Se requiere de la intencionalidad, de la capacidad de representar del cerebro. Gracias a dicha capacidad surge el lenguaje, el cual también permite no solo representar, sino además relacionarnos con el mundo de forma individual y colectiva, por ejemplo, por medio de los actos de habla. Así, la intencionalidad puede ser colectiva, cuestión que ocurre cuando varios agentes se relacionan cooperativamente. A partir de tal relación surge un compromiso y, ulteriormente, la asignación de funciones de estatus a objetos, personas o entidades. Usualmente, dichas funciones se establecen por medio de las declaraciones, y de la iteración de aquellas, todo lo cual causa la aparición de sistemas de poderes deónticos, con deberes y derechos cada vez más abstractos y complejos. Solo a partir de la intencionalidad colectiva, las funciones de estatus, los marcadores, los sistemas de poderes deónticos y las declaraciones puede construirse la realidad social, dependiente de nuestras mentes y actitudes.

29 "La obligación puede ser una razón independiente de deseo para una acción y con todo motivar esta porque puede ser el fundamento de un deseo para desarrollar una acción que constituye la satisfacción de la obligación, op. cit., p. 129, énfasis en original. 
En la siguiente sección examinaremos de qué forma opera el establecimiento de la responsabilidad penal internacional a la luz de la teoría de la realidad social de Searle. Para tales efectos, emplearemos el aparataje teórico de los actos de habla, explicado en la primera sección, y de la realidad social, descrito en la presente. Teniendo en cuenta ambas teorías podrá desarrollarse de qué forma la responsabilidad penal es un hecho producto de declaración y, por tanto, eminentemente institucional.

\section{El establecimiento de la responsabilidad penal internacional: hecho institucional serleano. Reflexiones a partir del caso Lubanga}

La iteración de funciones de estatus da lugar a sistemas de poderes deónticos cada vez más abstractos y complejos. Piénsese lo que sucede, por ejemplo, con Max, un ciudadano chileno mayor de edad, profesor de la universidad, decano de su facultad y miembro de una sociedad científica. En tanto mayor de edad, tiene derecho a votar en elecciones. Pero en la medida en que trabaja y recibe un salario debe pagar impuestos. A su vez, ser decano le confiere una serie de deberes y derechos sobre otros pares académicos, amén del reconocimiento que recibe de los mismos por tener ese cargo. Finalmente, como miembro de una sociedad científica, está facultado para consignar tal membresía en su $\mathrm{CV}$ y tiene derecho a asistir a los congresos anuales organizados por aquella sociedad. En síntesis, Max está inserto en una compleja red de poderes deónticos como consecuencia de la iteración de funciones de estatus típica de la realidad social. En efecto, ser mayor de edad, ciudadano, trabajador y profesor con prestigio y reconocimiento entre pares explican su comportamiento social, político, tributario y académico.

Ahora bien, la tesis que defenderemos en esta sección es que el derecho penal internacional es, justamente, un trascendental sistema de poderes deónticos, uno que surge de un tipo de intencionalidad colectiva que trasciende culturas y prácticas particulares. Solo los poderes deónticos asociados al derecho penal internacional permiten establecer la responsabilidad criminal a nivel internacional, yendo más allá de las culturas o prácticas sociales particulares. Un caso concreto apoyará nuestra tesis así como el análisis efectuado a la luz de la filosofía de Searle. 
El 14 de marzo de 2012 la Sala de Primera Instancia I de la CPI dictó sentencia en el caso "Prosecutor v. Thomas Lubanga" pronunciando las siguientes palabras: “(...) the Chambers finds Mr. Thomas Lubanga Dyilo: GUILTY of the crimes of conscripting and enlisting children under the age of fifteen years into the FPLC and using them to participate actively in hostilities with the meaning of Articles 8(2)(e)(vii) and 25 (3)(a) of the Statute from early September 2002 to 13 august 2003 (...)"30.

Las mencionadas palabras son un acto ilocucionario del tipo declarativo en la medida en que tuvieron la precisa intencionalidad de crear en el mundo el hecho descrito en el dispositivo de fuerza ilocucionario: la responsabilidad de Thomas Lubanga por los hechos concretos que le fueron imputados y que fueron calificados de crímenes de guerra según el Tratado de Roma.

Esa declaración fue formulada por un sujeto dotado de investidura (la Sala de Primera instancia del CPI, de acuerdo con los artículos 1 a 4 y 34 a 52 del Estatuto); en ejercicio de la competencia conferida a esta en razón de materia, tiempo, personas y lugar (artículos 5 a 12), y una vez terminado el procedimiento establecido (regulado, entre otros, en los artículos 13 a 19 y 53 y siguientes), esto es, aplicadas un conjunto de instituciones extralingüísticas prescritas también en el Tratado, aunque no solo estas.

Las reglas aplicadas por el CPI al momento de efectuar la declaración, son reglas constitutivas, en la medida en que hicieron posible que las palabras pronunciadas de esa forma, y en ese contexto contaran como una declaración de responsabilidad y produjeran los efectos que le son propias. Que, una vez formuladas, Thomas Lubanga se convirtiera en condenado, culpable de los crímenes que le fueron atribuidos, y debiera soportar la pena privativa de libertad que posteriormente se le impuso; que los órganos competentes debieran aplicarla; que recayera sobre el condenado un reproche universal por su actuación; se reafirmara en la comunidad internacional la vigencia de los derechos humanos tutelados por el Estatuto, entre muchos otros efectos derivados de esa declaración y que forman parte de la gama de actos perlocucionarios que se siguen de una declaración como la que examinamos aquí.

30 En http://www.icc-cpi.int/iccdocs/doc/doc1379838.pdf, última consulta 17.02.2013. Énfasis en el original. 
Esas reglas constitutivas, por lo demás, comportaron la asignación de poderes convencionales o arbitrarios a las palabras pronunciadas (funciones de estatus), esto es, funciones que no derivaban de su naturaleza intrínseca, y que sin esa intencionalidad no tendrían. Sin ese poder convencional, las palabras pronunciadas por el CPI no hubieran tenido la fuerza de una condena, ni habrían generado los efectos descritos en la persona de Thomas Lubanga o la comunidad internacional o en los Estados parte.

Según es posible apreciar, la responsabilidad penal internacional -al igual que cualquier otra clase de responsabilidad- puede ser vista como un hecho institucional, que surge a la realidad social bajo la forma de $X$ cuenta como $Y$ en $C$ descrita por Searle, en la medida en que es la intencionalidad colectiva la que determina que determinadas palabras pronunciadas por un tribunal $(X)$, en cierto contexto y tras cumplirse reglas sustantivas y procedimentales (en $C$ ) cuenten como una declaración de responsabilidad, y produzcan en el mundo los efectos convencionales establecidos por las reglas vigentes.

Como hecho institucional, la responsabilidad es un hecho observador-dependiente, y que exhibe una ontología subjetiva. Nuestra tesis es que el carácter observador-dependiente con ontología subjetiva hace que la responsabilidad en el derecho penal internacional sea una institución histórica contingente, al igual que toda responsabilidad que se sigue de declaraciones de responsabilidad emanadas de instancias de resolución judicial. Los caracteres, condiciones y contornos de esta dependen de la intencionalidad colectiva vigente, sin perjuicio de que, como analizaremos, es posible concebir mecanismos que aseguren su pervivencia en relación con conductas que se conciben como especialmente graves y merecedoras de reproche.

Analizar la responsabilidad penal internacional como una institución, y someterla al análisis teórico propuesto por Searle ofrece muchos aspectos sugerentes. En particular, permite apreciar que el derecho internacional no tiene una estructura esencialmente diferente de los derechos internos y, en general, de las demás instituciones sociales, cuyo surgimiento puede ser siempre descrito por el juego de intencionalidad colectiva, asignación de funciones y reglas constitutivas, y sobre todo por la intermediación de actos de habla, en particular de la clase de las declaraciones. Que tampoco difieren en su ontología subjetiva, en tanto observador-dependiente, como sucede con todas las instituciones, cualquiera sea su clase. El hecho de que en los derechos internos la responsabilidad penal disponga 
de una forma más institucionalizada no le resta el carácter esencialmente convencional que deriva de su naturaleza de hecho social.

Por otra parte, permite apreciar su carácter histórico y explicar su evolución en el tiempo, así como encontrar una justificación interesante para uno de sus caracteres: la imprescriptibilidad, como se enuncia brevemente en el acápite final.

\section{La imprescriptibilidad de la declaración de responsabilidad. Un argumento a favor de la construcción de la realidad social}

El artículo 29 del Estatuto de Roma dispone que los crímenes de competencia de la CPI no prescribirán, de modo que la responsabilidad penal por tales hechos podrá ser establecida siempre y en cualquier tiempo, sin sujeción a límites temporales.

¿Cómo puede justificarse la referida regla desde un punto de vista institucional? En la clave que hemos venido analizando, la imprescriptibilidad puede ser entendida como un compromiso de los Estados por mantener una definición de comunidad internacional que presupone la represión y sanción de esos crímenes; y con ello, el reconocimiento de un límite inviolable que sirva de garantía para las generaciones futuras. Este vendría dado por el reconocimiento de que siempre será necesaria y justificada la declaración de responsabilidad por los crímenes que este sanciona ${ }^{31}$.

Una norma como la anterior podría considerarse como una forma de reafirmación de la intencionalidad colectiva que llevó a la celebración de ese tratado y un mecanismo adicional para asegurar el mantenimiento de la misma con independencia de las contingencias históricas, políticas y de cualquier clase que puedan suceder a futuro. Esto es, como un mecanismo para reducir la variabilidad de la responsabilidad penal internacional que podría derivar de su naturaleza ontológicamente subjetiva en atención al carácter

31 Para un análisis de las justificaciones a la prescripción, RAGUÉs I VALLÉs, Ramón. La prescripción penal: Fundamento y aplicación. Barcelona: Atelier, 2004, pp. 24-47. 
fundacional que se reconoce a la represión de determinados crímenes especialmente lesivos para la humanidad.

Esa es la intención que se advierte, por lo demás, en el Preámbulo del Tratado de Roma, en el que se declara:

(...) Conscientes de que los pueblos están unidos por estrechos lazos y sus culturas configuran un patrimonio común y observando con preocupación que este delicado mosaico puede romperse en cualquier momento,

Teniendo presente que, en este siglo, millones de niños, mujeres y hombres han sido víctimas de atrocidades que desafían la imaginación y conmueven profundamente la conciencia de la humanidad,

Reconociendo que esos graves crimenes constituyen una amenaza para la paz, la seguridady el bienestar de la humanidad,

Afirmando que los crimenes más graves de trascendencia para la comunidad internacional en su conjunto no deben quedar sin castigo y que, a tal fin, hay que adoptar medidas en el plano nacional e intensificar la cooperación internacional para asegurar que sean efectivamente sometidos a la acción de la justicia,

Decididos a poner fin a la impunidad de los autores de esos crimenes y a contribuir asi a la prevención de nuevos crimenes (...) ${ }^{32}$.

De este modo, y por mucho que la responsabilidad tenga una naturaleza institucional $\mathrm{y}$, con ello, una ontología subjetiva y contingente, existen mecanismos institucionales específicos que permiten asegurar su permanencia. Tal como hemos argumentado en este trabajo, estos poderes deónticos dan lugar no solo a derechos y deberes, sino además a sistemas institucionales internacionales cuya acción es particularmente relevante en el derecho penal internacional. En efecto, los crímenes de lesa humanidad no escapan a los sistemas de poderes deónticos que surgen de la intencionalidad colectiva, en este caso

32 En Decreto No 104 del Ministerio de Relaciones Exteriores, publicado en Diario Oficial de 6 de julio de 2009, promulga el Estatuto de Roma de la Corte Penal Internacional, en www.bcn. [Consultado el 6 de febrero de 2013]. 
producto de los acuerdos internacionales, y dentro de los cuales la regla de la imprescriptibilidad cumple una relevante función.

El que se asegure que la responsabilidad por los crímenes de genocidio, lesa humanidad, guerra y agresión siempre y en cualquier tiempo podrá ser declarada, constituye un mecanismo diseńado por el mismo sistema para asegurar la pervivencia de la intencionalidad colectiva que permite el mantenimiento del reproche universal por tales comportamientos, y una forma de asegurar el reconocimiento de los derechos humanos como elemento definitorio de la identidad de la comunidad internacional.

\section{Conclusión}

En este trabajo hemos argumentado que la filosofía de John Searle es relevante y reveladora de cómo se establece la responsabilidad en el derecho penal internacional. Lo es porque, tal como hemos defendido aquí, toda declaración de responsabilidad se establece mediante ciertos actos de habla: los actos ilocucionarios descritos en la primera sección. Sin embargo, para comprender el sentido ontológico de la declaración en el derecho penal internacional fue necesario abordar cómo surge tal institucionalidad, a partir de la intencionalidad colectiva. En efecto, existe un nexo entre lenguaje, mente y sociedad, que se elucida mediante otros elementos como las reglas constitutivas, la atribución de funciones de estatus y los poderes deónticos. Justamente, y tal como examinamos, la iteración de funciones de estatus permite crear instituciones cada vez más complejas y universales, que trascienden la particularidad de cada cultura concreta. Es gracias a dichas instituciones que puede establecerse la responsabilidad para crímenes de lesa humanidad, y encontrar justificación a su imprescriptibilidad. 
